\title{
Knowledge, attitudes and practices of obstetrical ultrasound in Conakry, Guinea
}

\section{Telly S. Y. ${ }^{1 *}$, Daniel William Athanasse Leno ${ }^{2}$, Moussa Kantara Camara ${ }^{2}$, Yolande Hyjazi², Namory Keita ${ }^{2}$}

\author{
${ }^{1}$ Department of Obstetrics and Gynecology, Ignace Deen National Hospital, Conakry University Hospital, Guinea \\ ${ }^{2}$ Department of Obstetrics and Gynecology, Donka National Hospital, Conakry University Hospital, Guinea
}

Received: 29 November 2016

Accepted: 26 December 2016

\section{*Correspondence: \\ Dr. Telly S. Y., \\ E-mail: sytelly@yahoo.fr}

Copyright: () the author(s), publisher and licensee Medip Academy. This is an open-access article distributed under the terms of the Creative Commons Attribution Non-Commercial License, which permits unrestricted non-commercial use, distribution, and reproduction in any medium, provided the original work is properly cited.

\begin{abstract}
Background: The authors report an initial assessment of the practice of obstetrical ultrasound in Conakry in order to make suggestions to improve the quality of services in Guinea.

Methods: It is about a cross-sectional study of three months (August $1^{\text {st }}$ to October $31^{\text {st }}, 2013$ ) conducted in Conakry. The study population consisted of health personnel performing fetal ultrasounds in Conakry and who agreed to participate in the survey. The data collected were about the socio-professional characteristics of the service providers, their knowledge and attitudes. The data were analyzed in a simple descriptive statistical analysis way. The results were analyzed according to the norms and standards issued by the French Fetal Ultrasound College and the National Technical Committee for Prenatal Diagnosis Ultrasound.

Results: Twenty one service providers over twenty-six (80.8\%) were male (80.8\%) aged 40-49 years old (46.2\%), obstetrician-gynecologists (76.9\%), working in a public hospital $(46.2 \%)$ and not having an ultrasound degree $(59.2 \%)$. Eight service providers over twenty-six $((30.8 \%)$ affirmed knowing the recommended period for a fetal biometry. The majority $(60 \%)$ indicated measuring the nuchal translucency and $85.2 \%(22 / 26)$ the craniocaudal length. The anatomical landmarks were not correctly identified in $75.2 \%$ of cases for the biparietal and the head circumference and in $63.8 \%$ of cases for abdominal circumference. Nine service providers over twenty-six (34.6\%) affirmed explaining the limitations of ultrasound. Eighteen devices over twenty-six $(69.2 \%)$ had more than 9 years of age, $73 \%$ (19/26) of them did not have a vaginal probe and 65.3\% (17/26) did not have a pulsed wave Doppler.

Conclusions: Improving the quality of the practice of obstetrical ultrasound in Guinea goes through training of service providers, establishing distribution and compliance with norms and standards as well as quality control of ultrasound devices.
\end{abstract}

Keywords: Attitudes, Guinea, Knowledge, Obstetrical ultrasound, Practices

\section{INTRODUCTION}

In recent years, the health sector has undergone profound changes that are driven by the concern of providing quality care while controlling costs. Obstetrical ultrasound is not exempt of this need for quality control. In developed countries, the establishment of norms and standards, as well as legislation, has enabled supervising the practice of obstetrical ultrasound. ${ }^{1-3}$ In Africa, obstetrical ultrasound has experienced in recent years some development especially in urban areas. However, measures regulating its practice have not been associated with this development. ${ }^{4}$ The lack of regulation can lead to non controlled practices, responsible for harmful abuses both to the mother and her fetus also to the health system. ${ }^{5,6}$ 
In Guinea, obstetrical ultrasound is practiced by service providers having very different backgrounds, giving way to thinking that a big variability might exist in the knowledge of norms and standards as well as the practice of obstetrical ultrasound. We conducted this study to assess the knowledge, attitudes and practices of obstetrical ultrasound service providers in Conakry, in order to make suggestions to improve the quality of services in Guinea.

\section{METHODS}

It is a cross-sectional study of three months duration (August 1st to October 31st, 2013) carried out in Conakry (Guinea). The study population consisted of health personnel performing obstetrical ultrasounds in the town of Conakry who agreed to voluntarily participate in the survey. We have initially identified 31 obstetrical ultrasound service providers in the city of Conakry. The data collection was carried out on the obstetrical ultrasound practice sites by a gynaecologist-obstetrician pollster, through interview using a semi-structured questionnaire with open and closed questions, or single or multiple choice questions. The questionnaire was completed by the service provider in the presence of the pollster by checking the right answer(s). The socioprofessional characteristics of the service providers, their knowledge, attitudes and practices were the main variables collected. The parameters of ultrasound devices were also collected. The data collected were subject to a simple descriptive statistical analysis. The results were analyzed according to the norms and standards enacted by the French Fetal Ultrasound College (FFUC) and the National Technical Committee for Prenatal Diagnosis
Ultrasound (NTCPDU). ${ }^{2,7}$ An informed consent form was previously read and accepted by the sonographers, specifying that participation in the survey was free and voluntary, that it would take place under condition of anonymity and that the different information collected would be kept strictly confidential and would only be used in the framework of this study.

\section{RESULTS}

From the thirty-one obstetrical ultrasound service providers listed in Conakry, only twenty-six had accepted to participate voluntarily in the study, making it an acceptance rate of $83.8 \%$. Being unavailable and non compliance with data collection procedures were the main reasons given by the five service providers (16.2\%) who did not participate in the study.

\section{Socio-professional characteristics of ultrasound service providers}

The average age of service providers was 45 years old (37 years old and 66 years old). The age group 40-49 years old accounted for $46.2 \%(12 / 26)$, followed by the age group 50-59 years old $(30.8 \%)$. Twenty-one service providers over twenty-six $(80.8 \%)$ were male. Regarding occupation, obstetricians-gynecologists represented $76.9 \%(20 / 26)$ of the total number of professionals involved in our study, followed by radiologists $(11.5 \%)$ and general practitioners (11.5\%). ifteen service providers over twenty six $(57.6 \%)$ were employed in the public sector: $80 \%(12 / 15)$ in University Hospitals (UH) and $20 \%(3 / 15)$ in the Communal Medical Centers (CMC) and Health Centers (HS).

Table 1: Knowledge of norms and standards.

\begin{tabular}{|lll|}
\hline Knowledge of norms and standards & Yes n (\%) & No n (\%) \\
Frequency of an abdominal probe & $20(76.9 \%)$ & $6(23.1 \%)$ \\
Frequency of a vaginal probe & $21(80.8 \%)$ & $5(19.2 \%)$ \\
Nomber of ultrasounds during a normal pregnancy & $23(88.3 \%)$ & $3(11.7 \%)$ \\
Recommended schedule to perform the three ultrasounds & $19(73.3 \%)$ & $7(26.7 \%)$ \\
Best of times to perform a fetal morphology & $20(76.9 \%)$ & $6(23.1 \%)$ \\
Best of times to perform a fetal biometry & $8(30.8 \%)$ & $18(69.2 \%)$ \\
Best of times to measure the nuchal translucency in the $1^{\text {st }}$ & $23(87.1 \%)$ & $3(12.9 \%)$ \\
trimester & & \\
Meaning of the nuchal translucency & $14(52.9 \%)$ & $12(47.1 \%)$ \\
Interval between two fetal biometry ultrasounds & $9(33.3 \%)$ & $17(66.7 \%)$ \\
\hline
\end{tabular}

\section{FAttitudes of ultrasound service providers}

Fifteen service providers over twenty six (57.6\%) claimed to be on time for consultation. Before starting the ultrasound: $73.1 \%(19 / 26)$ of service providers indicated accepting a person accompanying the patient in the ultrasound room; $84.6 \%(22 / 26)$ said they question the patient about her medical history and the course of her pregnancy; 76.9\% (20/26) reported recalling the purpose of ultrasound to the patient and $34.6 \%$ (9/26) claimed to give to the patient information about the limitations of ultrasound. During the ultrasound examination: fifteen service providers out of twenty six $(57.6 \%)$ reported alternating mutism and commentary; six service 
providers over twenty-six $(23.1 \%)$ declared commenting on the examination process and three service providers out of twenty six $(115 \%)$ reported not speaking except to answer the patient's questions. At the end of the examination, when there is no feature, $53.1 \%$ of the service providers indicated that the examination is normal recalling the limitations, $15.4 \%$ (4/26) affirmed that the fetus is normal recalling the limitations of the examination, and $11.5 \%(3 / 26)$ indicated that the fetus is normal. Regarding the announcement of fetus' gender, $69.2 \%(18 / 26)$ of service providers declared that they asked the woman if she wants to know about it; $26.9 \%$ $(7 / 26)$ reported that they waited until the patient had requested and $3.8 \%(1 / 26)$ refused to tell the patient.

Table 2: Practice of ultrasound service providers.

\begin{tabular}{|lll|}
\hline Practice of service providers & Yes n (\%) & No n (\%) \\
\hline $\begin{array}{l}\text { Systematic Measurement of the CCL } \\
\begin{array}{l}\text { Systematic Measurement of the } \\
\text { nuchal translucency }\end{array}\end{array}$ & $22(85.2 \%)$ & $16(60 \%)$ \\
\hline $\begin{array}{l}\text { Compliance with the measure criteria } \\
\text { of the BIP and the HC }\end{array}$ & $6(24.8 \%)$ & $20(75.2 \%)$ \\
\hline $\begin{array}{l}\text { Compliance with the measure criteria } \\
\text { of the AC }\end{array}$ & $9(36.2 \%)$ & $17(63.8 \%)$ \\
\hline $\begin{array}{l}\text { Types of ultrasound report used } \\
\text { Stereotyped (CNGOF, CFEF...) }\end{array}$ & $5(17.9 \%)$ & $21(82.1 \%)$ \\
\hline Personal & $21(82.1 \%)$ & $4(17.9 \%)$ \\
\hline
\end{tabular}

\section{Practice (Table 2 and Figure 1)}

Concerning years of service in the ultrasound practice (Figure 1), the majority $(57.6 \%)$ of service providers claimed to have over 10 years of practice and $26.7 \%$ of them said they have between 6 and 10 years of practice.

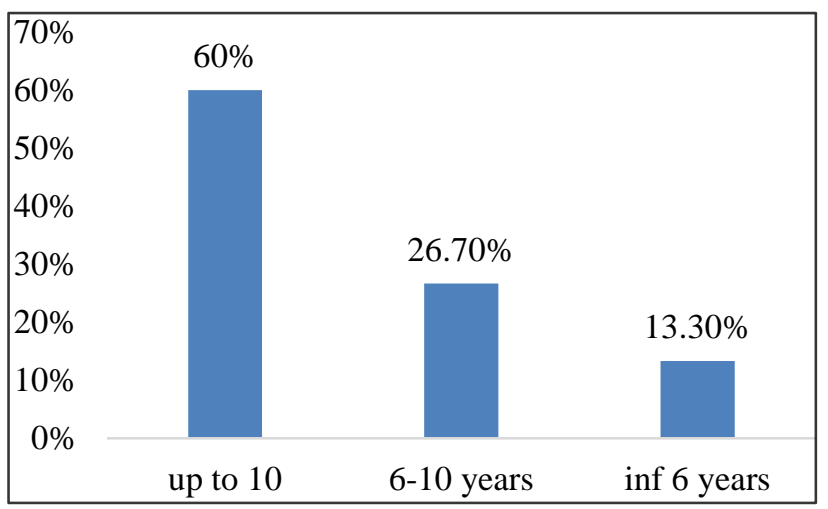

Figure 1: Distribution of service providers according to the years of ultrasound practice.

Twenty-two service providers over twenty-six (85.2\%) claimed they systematically measure the craniocaudal length (CCL) and sixteen service providers over twenty six $(60 \%)$ indicated measuring the nuchal translucency (NT).

Six service providers over twenty-six $(24.8 \%)$ annotated correctly anatomical landmarks of a section of the biparietal (BIP) and the head circumference (HC). Likewise, nine service providers over twenty-six (36.2\%) identified correctly anatomical landmarks of a section of the abdominal circumference (AC).

Upon discovery of a fetal malformation that can legally justify a medical termination of pregnancy (MTP): 53.8\% of service providers indicated considering it as an eventuality , $26.9 \%$ said they did it in such a way that the patient herself addresses the subject, $15.4 \%$ reported never speaking of MTP and 3.8\% affirmed considering it as a possibility.

Regarding the type of report used, twenty-one service providers over twenty six $(82.1 \%)$ reported using personal reports and five service providers over twenty six $(17.9 \%)$ affirmed using stereotyped reports ((FFUC, National college of French gynecologists and obstetricians: NCFGO...).

\section{Characteristics of ultrasound devices}

Eighteen ultrasound devices over twenty-six (69.2\%) were at most 9 years of age. Nineteen out of twenty six devices $(73 \%)$ did not have a vaginal probe; Seventeen devices over twenty-six $(65.3 \%)$ did not have a pulsed Doppler. However all the devices had a "TM" (Time Movement) mode.

\section{Perspectives}

Twenty-five service providers over twenty-six (96\%) wanted training in obstetrical ultrasound: Fifteen service providers over twenty-five $(60 \%)$ wanted to have training so that at the end they have a diploma and the ten others (40\%) wanted an advanced training course. 


\section{DISCUSSION}

Our study presents weak points that are the small sample and the fact of limiting the study to Conakry only. Despite these biases, our sample represents more than $90 \%$ of obstetrical ultrasound service providers in Guinea.

However, the originality of our study lies in the fact that, to the best of our knowledge, this is the first study to assess knowledge and practice of obstetrical ultrasound in Guinea. The acceptance rate in our study $(83.8 \%)$ appears satisfactory compared to the one found in a similar survey in France and lower than the one found by Moïfo and coll. in Cameroon. ${ }^{8,9}$

The average age of service providers is inferior to that of 51 years of age according to the study done by Matar and coll. ${ }^{10}$ In our study, the majority $(77 \%)$ of obstetrical ultrasound service providers is over 40 years of age. The proportion of service providers under 40 years of age was nearly two and a half times less than the one found by Moreira and coll., which is of $15.4 \%$ and $41 \%$ respectively. This result shows that our service providers are aging. ${ }^{11}$ There is therefore the need to train young people (doctors and midwives) to the practice of obstetrical ultrasound.

Regarding the profession, the proportion of gynecologists and obstetricians in our study is consistent with previous studies. $^{8,10,11}$ This finding can be explained on one hand by the fact that they constitute the majority of obstetrical ultrasound prescribers and secondly because they also receive patients referred by midwives and other health professionals. The absence of a midwife in our population can be explained by the lack of an obstetrical ultrasound training curriculum for this professional category. However, it is not possible that all obstetrical ultrasound be performed by specialists. Screening Obstetrical ultrasound must by definition be part of a practice of community care. As such, midwives who practice the majority of pre-natal consultations must be able to perform screening obstetrical ultrasound. The impact of the practice of obstetrical ultrasound by midwives in reducing morbidity and maternal and perinatal mortality in developing countries has been confirmed by recent studies. ${ }^{12-14}$

In our study, the majority (59.2\%) of service providers do not have a degree of obstetrical ultrasound. This could be explained by the lack of formal obstetrical ultrasound training. Very often, this training is included in the observational internships with no real educational content. It is obvious that the lack of formal training opens doors to misinterpretation of ultrasound images leading to misdiagnoses that can lead to inappropriate decision making for the mother and the fetus. This could explain the difference in the level of knowledge and practice of obstetrical ultrasound service providers in Guinea. It appears therefore, the need for obstetricians and midwives to have in their university courses, a formal training in obstetrical ultrasound. The creation of an inter-university obstetrical ultrasound degree could contribute effectively to improving the practice of this examination. Initial training, continuing education and regular and sufficient practice of obstetrical ultrasound are the essential tripod to guarantee expertise.

Fifteen service providers over twenty six $(57.7 \%)$ who were asked said they practice in the public sector. Our results are similar to those of African studies [5, 18] and contrary to that of Boog whose study revealed that $86 \%$ of service providers practice in the private sector. One of the explanations could be the lack of private health facilities in Guinea. ${ }^{8}$

The number of recommended screening obstetrical ultrasound during a normal pregnancy varies according to countries and regions. In France, the NTCPDU recommends three screening ultrasounds during followup of normal pregnancy, each of the three ultrasounds having specific goals. ${ }^{7}$ On the other hand, other countries such as Germany and the United Kingdom only recommend two obstetrical ultrasounds during a normal pregnancy follow-up. ${ }^{15}$ This situation contrasts with that of most African countries, where there are no recommendations regarding the number and period of obstetrical ultrasound examinations during a normal pregnancy. This finding may be responsible for medical overconsumption often without obvious benefit to the health of the mother and the fetus. Therefore, it is important that norms and standards are established by the Guinean Society of Obstetrics and Gynecology (GSOG) to better supervise the practice of obstetric ultrasound in Guinea.

Our study shows a shortfall in the level of knowledge of sonographers since $69.2 \%$ (18/26) of them do not know the ideal time to perform a fetal biometry, $47.1 \%(12 / 26)$ do not know the meaning of a nuchal translucency, and $66.7 \%(17 / 26)$ do not know the recommended interval between two fetal biometry ultrasounds.

Our study shows a shortfall in the communication between service providers and patients. Indeed, only one third $(34.6 \%)$ of service providers affirmed that they provide information on the limitations of the examination to patients, about one service provider over four $(23.1 \%)$ declared that he or she comments on the proceedings of the ultrasound examination. Regarding the announcement of fetal gender, one service provider over four $(26.9 \%)$ indicated that he or she waits until the patient makes the request. It is obvious that in the practice of the medical profession, everyone has the right to be informed about their condition. It is therefore essential to explain to patients the examination they are being proposed, its indications, purpose, disadvantages, limitations, in order to obtain their free and informed consent. In this regard, the FFUC prepared a background paper to be given to the patient before performing the obstetrical ultrasound. ${ }^{16}$ 
However; the delivery of this document is not mandatory, but highly recommended, in addition to verbal information to future parents.

The first trimester ultrasound has known for a decade significant progress in revealing vital information to the monitoring of pregnancies. Ultrasound so called of "12 GW" performed between 11 and 14 Gestational weeks corrected by a cranio caudal length (CCL) between 45 and $84 \mathrm{~mm}$ allows dating of pregnancy and is the most efficient screening test for fetal Down syndrome (trisomy 21 syndrome) when measurement of nuchal translucency (NT) is interpreted based on maternal age and the CCL. ${ }^{17}$ Many factors encourage to perform a precise dating: date of last menstrual period (LMP) often poorly known, through memory for both the day of the week and the month, variation in follicular period, occurrence of metrorrhagia" anniversary period". ${ }^{17,18}$ The proportion of service providers who declared measuring the NT in our study is much lower than the one found in the literature. ${ }^{9,19}$ However, it was not possible to assess the quality of these various biometric measurements because of the absence of these items in our survey form.

Fetal ultrasound is based largely on the quality of fetal biometrics, through the identification of key anatomical structures. It is in this context that Dudley and Chapman proposed in 2002 criteria for qualitative assessment of biometric sections. ${ }^{20}$ These criteria are specific for each parameter and they are made on the basis of fetal biometrics references. ${ }^{21-23}$ The identification and study of these anatomical structures also constitute the basis of the detailed morphological study of the fetus. The analysis of our results shows a deficiency in the practice of obstetrical ultrasound, since only one service provider over four $(24.8 \%)$ knew the key anatomical structures to identify when measuring the biparietal (BIP) and head circumference $(\mathrm{HC})$; and a service provider over three $(36.2 \%)$ correctly indicated the key anatomical structures to identify when measuring abdominal circumference (AC).

In our series, more than four service providers over five $(82 \%)$ used personal reports. This situation may be confusing and a source of non-compliance with norms and standards. In France, the NTCPDU recommended key elements to be included in the report of the screening ultrasound examination of the 1st, 2nd and 3rd trimesters. $^{7}$ For the approach quality of practice of obstetrical ultrasound in Guinea, we recommend a harmonization of all reports under the auspices of the GSOG.

The quality of the equipment is an essential element for the reliability of the ultrasound findings. As such, the NTCPDU has in its 2005 report issued the following quality criteria: a machine under 7 years with the presence of a pulsed Doppler cine loop with a capacity of at least 200 images, with at least two probes (one vaginal), one zoom not degrading, the ability to measure to the $1 / 10$ th of $\mathrm{mm}$, and with an up to date maintenance register. ${ }^{7}$ It is also important that it has a pedal to freeze images, allowing the service provider to free his or her hands in order to manipulate the probe and mobilize the fetus if necessary. According to Nisand and Pasquet, technology evolution is such that 7 years should be the limit for the use of machines, and after 10 years, they would become obsolete. ${ }^{24,25}$ Considering these criteria, about one third $(30.8 \%)$ of the ultrasound equipment used in Guinea would be obsolete. This could be explained by the lack of legislation on the assessment of the quality of ultrasound equipment. Therefore, the implementation of legislation and an accreditation and control body of ultrasound devices could help to improve the quality of the practice of fetal ultrasound in Guinea. The objective of quality control is to improve and maintain a satisfactory level of quality of ultrasound devices.

\section{CONCLUSION}

We showed in this study a lack of training of service providers in obstetrical ultrasound, a low level of knowledge, attitudes and practices, as well as the obsolete nature of ultrasound devices.

Improving the quality of the practice of obstetrical ultrasound in Guinea goes unavoidably through formal training of service providers, establishing, distribution and compliance with the norms and standards and the quality control of ultrasound devices. The implementation of these measures as well as legislation, could contribute effectively to improving the quality of obstetrical care in Guinea.

\section{ACKNOWLEDGMENTS}

We thank all obstetrical ultrasound service providers who agreed to take part in this study.

Funding: No funding sources

Conflict of interest: None declared

Ethical approval: The study was approved by the Institutional Ethics Committee

\section{REFERENCES}

1. Anonyme. ACR-ACOG-AIUM-SRU Practice guideline for the performance of obstetric ultrasound. Available from: http://www.acr.org/ /media/f7bc35bd59264e7cbe64 8f6d1bb8b8e2.pdf.

2. Collège français d'échographie fœtale (CFEF). Guide d'examen échographique du fœetus à 12, 22 et 32 SA. Available from: https://www.cfef.org/archives/communication/guide1

3. Lansac J. Rapport du Comité national technique de l'échographie de dépistage prénatal. L'échographie de diagnostic 2010. Available from: http://www.cngof.asso.fr/D_TELE/100513_rapport_ echo.pdf. 
4. Gilani SA. Ultrasound training and research in developing countries. DSJUOG. 2011;5:297-320.

5. Mubuuke AG, Kiguli-Malwadde E, Businge F, Byanyima RK. Utilisation of obstetric sonography at a peri-urban health centre in Uganda.Pan African Medical Journal. 2011;7:24.

6. Kongnyuy EJ, van den Broek N.The use of ultrasonography in obstetrics in developing countries.Trop Doct. 2007;37:70-2.

7. Sureau C, Henrion R. Comité National Technique de l'Echographie de Dépistage Prénatal Rapport du Comité National Technique de l'Echographie de Dépistage Prénatal. Paris. Documentation française. 2005. 175 p.

8. Boog G, Guenier B. Enquête régionale dans les Paysde-la-Loire sur la qualité des échographies du premier trimestre de la grossesse. J Gynecol Obstet Biol Reprod. 2000;29:751-7.

9. Moifo B, Dzeukam A, Tebere H, Foumane P, Tambe J, Gonsu Fotsin J. Evaluation des connaissances et attitudes pratiques en échographie systématique du premier trimestre de la Grossesse au Cameroun. Health Sci Dis. $2013 ; 14(3): 1-6$.

10. Matar M, Picone O, Dalmon C, Ayoubi JM. Evaluation des connaissances des échographistes sur les clichés d'échographie de dépistage du deuxième trimestre recommandé par le Comité technique national de l'échographie. J Gynecol Obstet Biol Reprod. 2013;42:473-8.

11. Moreira PM, Guèye M, Faye Diémé ME, Mbaye M, Kane Guèye SM, et al. Obstetrical Ultrasound in Senegal: Knowledge, Attitude and Practice. J Womens Health, Issues Care. 2013;2:3.

12. Vangeenderhuysen $\mathrm{C}$, Abdellahi MB, Isselmou S. La formation des sages-femmes en échographie obstétricale dans les pays en développement : pourquoi et comment ? 2002; 31: 100-6

13. Kimberly HH, Murray A, Mennicke M, Liteplo A, Lew J, Bohan JS, et al. Focused maternal ultrasound by midwives in rural Zambia. Ultrasound Med Biol. 2010;36:1267-72.

14. Bonnett TJ, Roberts AL, Houlden EM. Obstetric ultrasound training for midwives in a resource-poor setting.RCOG World Congress 2013 Poster \# EP5.50 Liverpool UK, 24-26 June 2013.

15. Echographie au cours de la grossesse en l'absence de facteurs de risqué. Service des recommandations et
Références professionnelles. Décembre 1998. http//www.anaes.fr. Consulté en ligne le 21 novembre 2013.

16. Enligne: http://www.cfef.org./archives/ communication/guide1.html consulté le 21 novembre 2013.

17. Collège français d'échographie fotale (CFEF). En ligne:

http://www.cfef.org./archives/communication/guide1 .html consulté le 21 novembre 2013.

18. Salomon LJ, Bernard JP, Ville Y. First trimester ultrasound should be a tailored examination $\mathbf{J}$ Gynecol Obstet Biol Reprod. 2004;33(5):375-7.

19. Cisse R, Ouadréogo A, Tapsoba T, Lougué C, Ouedraogo CMR, Ouattara T, Lankoande J, et Koné B. Biométrie fœtale ultrasonore dans la ville de Ouagadougou, Burkina Faso. A propos d'une cohorte de 126 gestantes. J Radiol. 2000;81:509-15.

20. Jaumain P, Puech F, Subtil D, Bourgeot PDJ. Evaluation de la qualité des échographies du premier trimestre dans le cadre du dépistage intégré de la trisomie 21 fotale. $2005: 1-6$.

21. Dudley NJ, Chapman E. The importance of quality management in fetal measurement. Ultrasound Obstet Gynecol. 2002;151(3):333-7.

22. Chitty LS, Altman DG, Henderson A. Charts of fetal size: 2. Head measurement. Br J Obstet Gynaeco.1 1994;101(1):35-43.

23. Chitty LS, Altman DG, Henderson A et al. Charts of fetal size: 4. Femur lengh. Br J Obstet Gynaecol. 1994;101(2):132-5.

24. Chitty LS, Altman DG, Henderson A et al. Charts of fetal size: 3. Abdominal measurement. Br J Obstet Gynaecol. 1994;101(2):125-31.

25. Nisand I. The practice of ultrasonography in gynecology-obstetrics: standard performance and results. J Gynecol Obstet Biol Reprod. 1994;23:532$8 .$.

26. Pasquet C, Sicot C. Risque et responsabilité en échographie anténatale. Concours Méd. 1998;120:318-21.

Cite this article as: Telly SY, Leno DWA, Camara MK, Hyjazi Y, Keita N. Knowledge, attitudes and practices of obstetrical ultrasound in Conakry, Guinea. Int J Reprod Contracept Obstet Gynecol 2017;6:585-90. 